\title{
Effects of L-Malate on Mitochondrial Oxidoreductases in Liver of Aged Rats
}

\author{
J.-L. WU ${ }^{1}$, Q.-P. WU ${ }^{1}$, Y.-P. PENG ${ }^{2}$, J.-M. ZHANG ${ }^{1}$ \\ ${ }^{1}$ Guangdong Provincial Key Laboratory of Microbial Culture Collection and Application, \\ Guangdong Institute of Microbiology, Guangzhou, China, ${ }^{2}$ Guangzhou Wondfo Biotech Co. Ltd, \\ South China University of Technology, Guangzhou, China
}

Received March 3, 2010

Accepted July 28, 2010

On-line November 20, 2010

\section{Summary}

Accumulation of oxidative damage has been implicated to be a major causative factor in the decline in physiological functions that occur during the aging process. The mitochondrial respiratory chain is a powerful source of reactive oxygen species (ROS), considered as the pathogenic agent of many diseases and aging. L-malate, a tricarboxylic acid cycle intermediate, plays an important role in transporting NADH from cytosol to mitochondria for energy production. Previous studies in our laboratory reported L-malate as a free radical scavenger in aged rats. In the present study we focused on the effect of L-malate on the activities of electron transport chain in young and aged rats. We found that mitochondrial membrane potential (MMP) and the activities of succinate dehydrogenase, NADH-cytochrome c oxidoreductase and cytochrome $\mathrm{c}$ oxidase in liver of aged rats were significantly decreased when compared to young control rats. Supplementation of L-malate to aged rats for 30 days slightly increased MMP and improved the activities of NADHdehydrogenase, NADH-cytochrome $\mathrm{c}$ oxidoreductase and cytochrome $c$ oxidase in liver of aged rats when compared with aged control rats. In young rats, L-malate administration increased only the activity of NADH-dehydrogenase. Our result suggested that L-malate could improve the activities of electron transport chain enzymes in aged rats

\section{Key words}

L-malate • Aging • Electron transport chain • Mitochondria

\section{Corresponding author}

Q.-P. Wu, Guangdong Institute of Microbiology, Guangzhou 510070, China. Fax: 86-20-8768-0942. E-mail: wuqp203@ yahoo.com.cn; microwjl@yahoo.com

\section{Introduction}

Oxygen radicals are continually produced as byproducts of aerobic metabolism and lead to damage of cellular macromolecules (Harman 1956, Beckman and Ames 1998, Drew and Leeuwenburgh 2002). Mitochondria are considered to be the most immediate targets of oxidative damage, and accumulation of such oxidative damage has been widely postulated to be a primary causal factor in the aging process (Harman 1972, Miquel et al. 1980). Mitochondrial dysfunction appears to contribute to a certain loss of function accompanying aging (Shigenage et al. 1994). Besides being the main site of ATP production, mitochondria are the predominant intracellular generators of ROS (reactive oxygen species), specifically superoxide anion radical $\left(\mathrm{O} 2 \bullet^{-}\right)$and its stoichiometric product, $\mathrm{H}_{2} \mathrm{O}_{2}$ (Chance et al . 1979, Kwong and Sohal 1998). The age-dependent changes in mitochondria, characterized by a decline in the activity of electron transport oxidoreductases (Kwong and Sohal 2000), reduced the ability of mitochondria to meet cellular energy demand (Hagen et al. 2002).

The electron transport chain (ETC) is located in the inner membrane of the mitochondria and consists of many oxidoreductases. The impairment of electron transfer between oxidoreductases of the mitochondrial electron transport chain causes the upstream components to become more electron-laden and susceptible to autoxidation, thereby decreasing respiratory activity and enhancing ROS production (Sohal 1991, 1994). Oxidative damage to the mitochondria DNA, manifested as oxidative modifications of nucleosides, mutations and 
deletions has been widely assumed to be related with the deleterious functional alterations in the activities of the electron transport oxidoreductases (Richter et al. 1995). It was hypothesized that the accumulation of somatic mutations of mtDNA leads to errors in the mtDNAencoded polypeptides (Cortopassi et al. 1992). These mutations in DNA-encoded proteins of the mitochondria could lead to mitochondrial dysfunction. Therefore, as mitochondria including the respiratory chain become more and more damaged higher amounts of free radicals are generated. This kind of a vicious cycle finally leads to non-functional mitochondria (Ozawa 1997).

L-malate is easily absorbed, comes into mitochondrion through cell membrane and promotes energy production in mitochondrion (Bobyleva-Guarriero and Lardy 1986). L-malate supplementation promotes a greater contribution of aerobic ATP production. It has been suggested that enhancing malate supplementation may activate ATP production from the tricarboxylic acid cycle through anaplerotic reactions (Bendahan et al. 2002). L-malate plays a central role in fostering the transport of cytosolic reduced nicotinamide adenine dinucleotide into mitochondria (Ferguson and Williams 1966, Chappel 1968). NADH and $\mathrm{FADH}_{2}$ produced by glycolysis and other cytosolic reactions were oxidized by ETC to produce ATP in the mitochondria. Recent studies suggest that feeding L-malate improves the performance during forced swimming by enhancing rate of energy metabolism and improves mitochondrial functions of aged rats by reversing oxidative stress (Wu et al. 2007, 2008). Studies also show that L-malate administration improves antioxidant functions and reduces lipid peroxidation (LPO) status in aged rats (Wu et al. 2008). It was supposed that L-malate may be a useful dietary supplement to increase overall mitochondrial metabolism. Therefore, in order to clarify the degree of the involvement of L-malate on energy metabolism, the objective of the present work was to investigate the effect of L-malate on the activities of respiratory chain oxidoreductases involved in ATP synthesis and transfer within the cell.

\section{Materials and Methods}

\section{Preparation of chemicals}

L-malate, enzymes, bovine serum albumin and all substrates were purchased from Sigma Chemical Company (St. Louis, MO, USA). Rhodamine 123 (Rh123) was also purchased from Sigma. All other chemicals used were of analytical grade and obtained from Guangdong HuanKai Microbial Sci. \& Tech. Co., Ltd., China.

\section{Animal preparation}

Male rats of Sprague-Dawley strain (SPF grade) were used in this study. They were healthy animals maintained and housed in large spacious cages and given food and water ad libitum. The animal room was well ventilated with a $12 \mathrm{~h}$ light: $12 \mathrm{~h}$ dark cycle and maintained at $21-23{ }^{\circ} \mathrm{C}$ throughout the experimental period.

\section{Experimental groups}

The animals were divided into two major groups, Group I: young rats (3-4 months old weighing about 180-220 g), Group II: aged rats (above 24 months old weighing approximately 480-560 g). These groups were further subdivided into two groups: one control group (Groups Ia, IIa) and one experimental group (Groups Ib, Ilb). Each group consisted of six animals.

Group Ia: young control rats, Group Ib: young treated rats (L-malate administration), Group IIa: aged control rats, Group IIb: aged treated rats (L-malate administration). L-malate $(0.21 \mathrm{~g} / \mathrm{kg}$ body weight per day) was administered via intragastric canula for 30 days. Control animals were given physiological saline alone. At the end of experimental period, animals were killed by decapitation. Liver was excised immediately and immersed in ice-cold physiological saline.

\section{Cell isolation}

The liver samples were quickly dissected, rinsed with ice-cold physiological saline and dried by blotting between two pieces of filter paper and accurately weighed. The liver tissue was dispersed into single cells by collagenase (Moldeus et al. 1978). Cell number was assessed by using a hemocytometer, and viability was determined by trypan blue exclusion. Viability was usually more than $90 \%$ in both age groups.

\section{Isolation of mitochondria}

Liver mitochondria were isolated by a modification of the technique described by Scholz et al. (2000). All isolation steps were performed at $0-4{ }^{\circ} \mathrm{C}$. Briefly, tissues were minced and homogenized in eight vol (w/v) of MSE solution (220 mM mannitol, $70 \mathrm{mM}$ sucrose, $5 \mathrm{mM}$ potassium HEPES and $2 \mathrm{mM}$ EDTA buffer, $\mathrm{pH}$ 7.4). The homogenate was centrifuged at 
$1200 \mathrm{~g}$ for $10 \mathrm{~min}$ and the pellet of nuclei and cell debris was discarded. The supernatant fraction was centrifuged at $12000 \mathrm{~g}$ for $10 \mathrm{~min}$. The mitochondrial pellet centrifuged at $12000 \mathrm{~g}$ was washed four times with MSE solution by centrifugation at $12000 \mathrm{~g}$ for $10 \mathrm{~min}$. The mitochondria pellet was suspended in the same buffer and stored at $-80^{\circ} \mathrm{C}$ until assayed. The mitochondrial protein concentrations were determined by the method of Bradford (1976) with bovine serum albumin as the standard.

\section{Mitochondrial membrane potential}

Mitochondrial membrane potential was monitored by fluorescence of Rh123 released from the mitochondria (Smith and Weidemann 1993). The Rh123 was used at a final concentration of $100 \mu \mathrm{M}$ by adding $20 \mu \mathrm{l}$ of Rh123 solution to $1.0 \mathrm{ml}$ cells suspension $\left(2.0 \times 10^{6}\right.$ cells $)$. The cells were incubated in dark at $37^{\circ} \mathrm{C}$ for $30 \mathrm{~min}$. Then, the cells were washed twice with PBS (150 g, $5 \mathrm{~min}$ ) and resuspended in PBS solution at $1 \times 10^{6}$ cells/ml for flow cytometric analysis with BectonDickinson FACSCalibur utilizing CellQuest Pro software. The stain cells were determined at an excitation wavelength of $495 \mathrm{~nm}$ and an emission wavelength of $535 \mathrm{~nm}$. A minimum of 8000 events were recorded per single measurement. Background fluorescence was corrected by the inclusion of parallel blanks. Mitochondrial membrane potential was expressed in arbitrary units (fluorescent intensity, FI). Cells were analyzed immediately after staining and always kept on ice in dark until measurement.

\section{Determination of enzyme activities}

The activities of all complexes were measured in triplicate at $30^{\circ} \mathrm{C}$, in a total reaction volume of $1 \mathrm{ml}$, using a Beckman DU-7400 spectrophotometer. The activity of NADH-dehydrogenase was measured by recording the decrease in the absorbance due to the oxidation of NADH at $340 \mathrm{~nm}$ with the reference set at $425 \mathrm{~nm}$ (Ferguson et al. 2005). The mitochondria were disrupted by freezing and thawing three times in $25 \mathrm{mM}$ potassium phosphate buffer ( $\mathrm{pH} 7.2)$ and then were added to a buffer containing $25 \mathrm{mM}$ potassium phosphate ( $\mathrm{pH} 7.4$ ), $5 \mathrm{mM} \mathrm{MgCl}, 2 \mathrm{mM} \mathrm{KCN}, 2 \mu \mathrm{g}$ antimycin $\mathrm{A}$, $2.5 \mathrm{mg}$ fat-free $\mathrm{BSA}, 100 \mu \mathrm{M} \mathrm{NADH}$ and $100 \mu \mathrm{M}$ ubiquinone-2. The NADH ubiquinone oxidoreductase activity was measured for $2 \mathrm{~min}$ and then again for another $2 \mathrm{~min}$ after rotenone ( $15 \mu \mathrm{M}$ final concentration) was added. The decrease in NADH activity after rotenone addition is the blank slope which was subtracted from the $\mathrm{NADH}$ slope before adding rotenone. An extinction coefficient of $6.22 \mathrm{mM} \cdot \mathrm{cm}^{-1}$ was used to calculate absolute changes.

The activity of succinate dehydrogenase was measured by monitoring the reduction of 2, 6-dichlorophenolindophenol (DCPIP) at $600 \mathrm{~nm}$ (Birch-Machin et al. 1994). Mitochonria were disrupted as above and preincubated in buffer containing $25 \mathrm{mM}$ potassium phosphate ( $\mathrm{pH} 7.2$ ), $5 \mathrm{mM} \mathrm{MgCl}_{2}, 20 \mathrm{mM}$ succinate at $30{ }^{\circ} \mathrm{C}$ for $10 \mathrm{~min}$ to fully activate the enzyme. After preincubation, $10 \mathrm{mM} \mathrm{KCN}, 2 \mathrm{mg}$ antimycin $\mathrm{A}, 2 \mathrm{mg}$ rotenone and $50 \mu \mathrm{M}$ DCPIP were added and baseline changes were recorded; $16 \mathrm{mg}$ ubiquinone was then added and the reduction was measured. An extinction coefficient of $19.1 \mathrm{mM}^{-1} \cdot \mathrm{cm}^{-1}$ was used to calculate absolute changes.

The activity of NADH-cytochrome c oxidoreductase was measured by following the increase in absorbance due to the reduction of ferricytochrome $\mathrm{c}$ at $550 \mathrm{~nm}$, with $580 \mathrm{~nm}$ as the reference wavelength (Ferguson et al. 2005). The reaction mixture consisted of $100 \mathrm{mM}$ potassium phosphate ( $\mathrm{pH} 7.4), 0.3 \mathrm{mM}$ EDTA, $80 \mu \mathrm{M}$ horse heart cytochrome c, $100 \mu \mathrm{M}$ NADH, $2 \mathrm{mM}$ $\mathrm{KCN}$ and $5 \mathrm{mM} \mathrm{MgCl}$. The reaction was initiated by the addition of disrupted mitochondria (5-15 $\mu \mathrm{g}$ of protein) and the increase in absorbance was monitored for $2 \mathrm{~min}$, after which rotenone ( $3.75 \mu \mathrm{M}$ final concentration) was added and the absorbance was monitored for additional $60 \mathrm{~s}$. An extinction coefficient of $19 \mathrm{mM}^{-1} \cdot \mathrm{cm}^{-1}$ was used to calculate absolute changes.

The activity of cytochrome c oxidase was measured by recording the decrease in absorbance due to the oxidation of ferrocytochrome $\mathrm{c}$ at $550 \mathrm{~nm}$, with $580 \mathrm{~nm}$ as the reference wavelength (Birch-Machin et al. 1994). The absorbance of the reaction mixture $(10 \mathrm{mM}$ potassium phosphate, $\mathrm{pH} 7.4,2 \mathrm{mg}$ rotenone, $0.45 \mu \mathrm{M}$ dodecyl maltoside and $15 \mu \mathrm{M}$ ferrocytochrome c) was measured for $1 \mathrm{~min}$ to monitor the stability of the reagents and to allow temperature equilibration. The reaction was then initiated by adding disrupted mitochondria (1-5 $\mu \mathrm{g}$ of protein) and the decrease in absorbance was monitored for additional $30 \mathrm{~s}$. To prepared ferrocytochrome c, $1 \%$ ferricytochrome c was reduced completely by dithionate and excess dithionate was removed by passing the solution through of Sephadex G-25. An extinction coefficient of $19.1 \mathrm{mM}^{-1} \cdot \mathrm{cm}^{-1}$ was used to calculate absolute changes. 

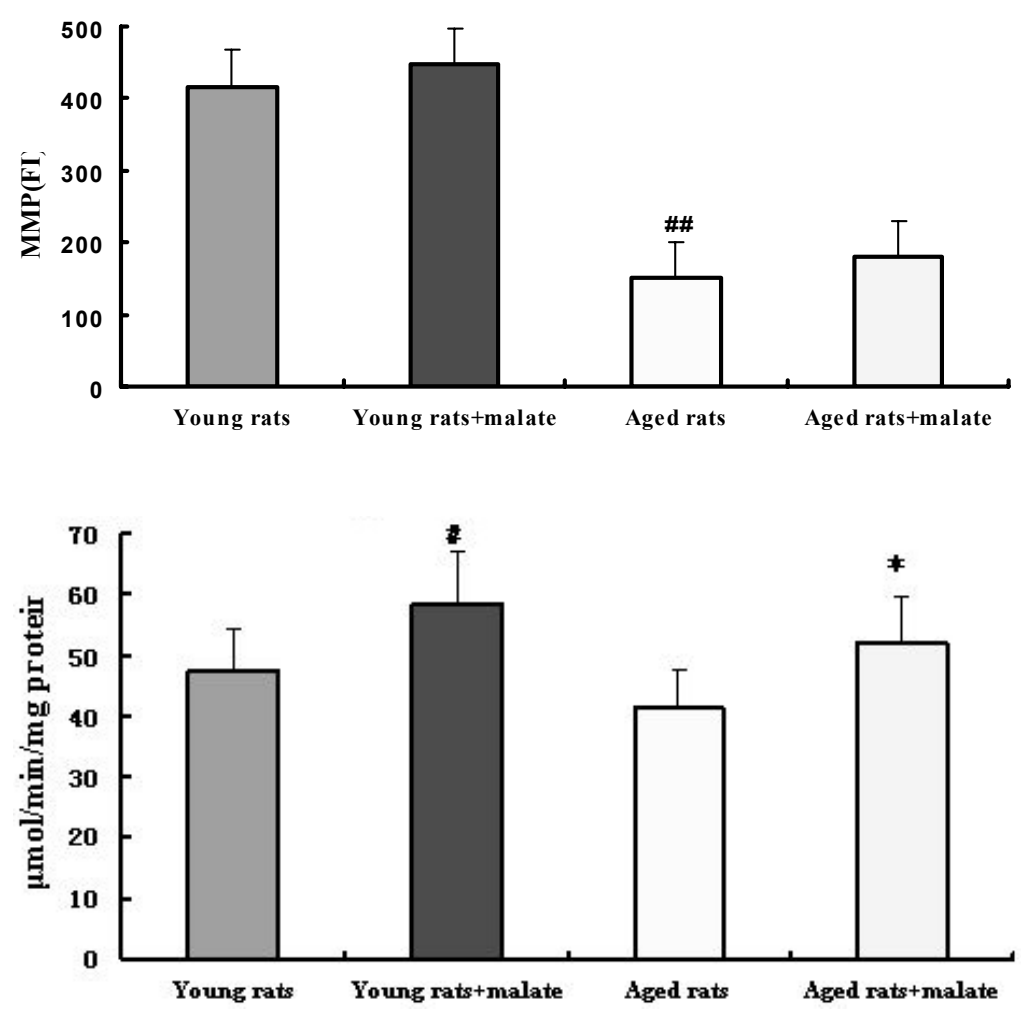

Fig. 1. Effect of L-malate on mitochondrial membrane potential in liver of young and aged rats. Values are given as means \pm S.D. $(n=4$, respectively). MMP was expressed in arbitrary units (fluorescent intensity, $\mathrm{FI}$ ). ${ }^{\#{ }^{\#} \mathrm{P}<0.01 \text { indicates }}$ significant difference compared with young rats (Group Ia).

Fig. 2. Activity of NADH-dehydrogenase in liver mitochondria of control and malate-treated young and aged rat. Values are the means \pm S.D. $(n=6$, respectively). $\quad{ }^{\#} \mathrm{P}<0.05$ indicates significant difference compared with young rats (Group Ia); ${ }^{*} \mathrm{P}<0.05$ indicates significant difference compared with aged rats (Group IIa).

\section{Statistical analysis}

The original data were tested with SPSS software. All the results were presented as mean \pm S.D. One-way analysis variance (ANOVA) was used for statistical analysis, and all tests were considered to be statistically significant at $* \mathrm{P}<0.05$ or $* * \mathrm{P}<0.01$.

\section{Results}

Figure 1 represents MMP in liver of young and aged rats before and after supplementation of L-malate. For this experiment we used a fluorescent dye Rh123, which accumulates in the mitochondria as a function of the inner mitochondrial membrane potential. MMP was decreased by $64.0 \%(\mathrm{P}<0.01)$ in liver of aged control rats (Group IIa) compared to young control rats (Group Ia). In aged rats supplemented with L-malate, hepatocellular mitochondrial membrane potential was only $10.2 \%$ higher than in aged control rats and this difference was not significant $(\mathrm{P}>0.05)$. There was also no significant difference between young treated rats (Group $\mathrm{Ib}$ ) and young control rats (Group Ia).

Figure 2 shows activity of NADHdehydrogenase in liver of young and aged rats before and after supplementation of L-malate. L-malate administration was found to enhance significantly the activity of NADH-dehydrogenase, the increase being
$23.2 \%$ in young treated rats and $24.8 \%$ in aged treated rats, compared with young and aged control rats (Group Ia and Group IIa), respectively. There was no significant difference between aged control rats and young control rats.

Figure 3 represents the activity of succinate dehydrogenase in liver of young and aged rats before and after supplementation of L-malate. The activity of succinate dehydrogenase was decreased by $51.6 \%$ $(\mathrm{P}<0.01)$ in liver of aged control rats (Group IIa) compared to young control rats (Group Ia). There was no significant difference between malate-treated rats (Group Ib and Group IIa) and control rats (Group Ia and Group IIa).

Figures 4 and 5 show the activities of NADHcytochrome c oxidoreductase and cytochrome c oxidase in liver of young and aged rats before and after supplementation of L-malate. The activities of these enzymes were found to be inhibited significantly in liver of aged control rats compared with young controls. The activity of NADH-cytochrome c oxidoreductase and cytochrome c oxidase in liver were decreased by $41.7 \%$ and $43.2 \%$, respectively, in aged controls. L-malate administration enhanced significantly the activities of these enzymes in liver during aging. The increase in NADH-cytochrome c oxidoreductase activity and cytochrome c oxidase activity by $76.6 \%$ and $66.3 \%$ was 

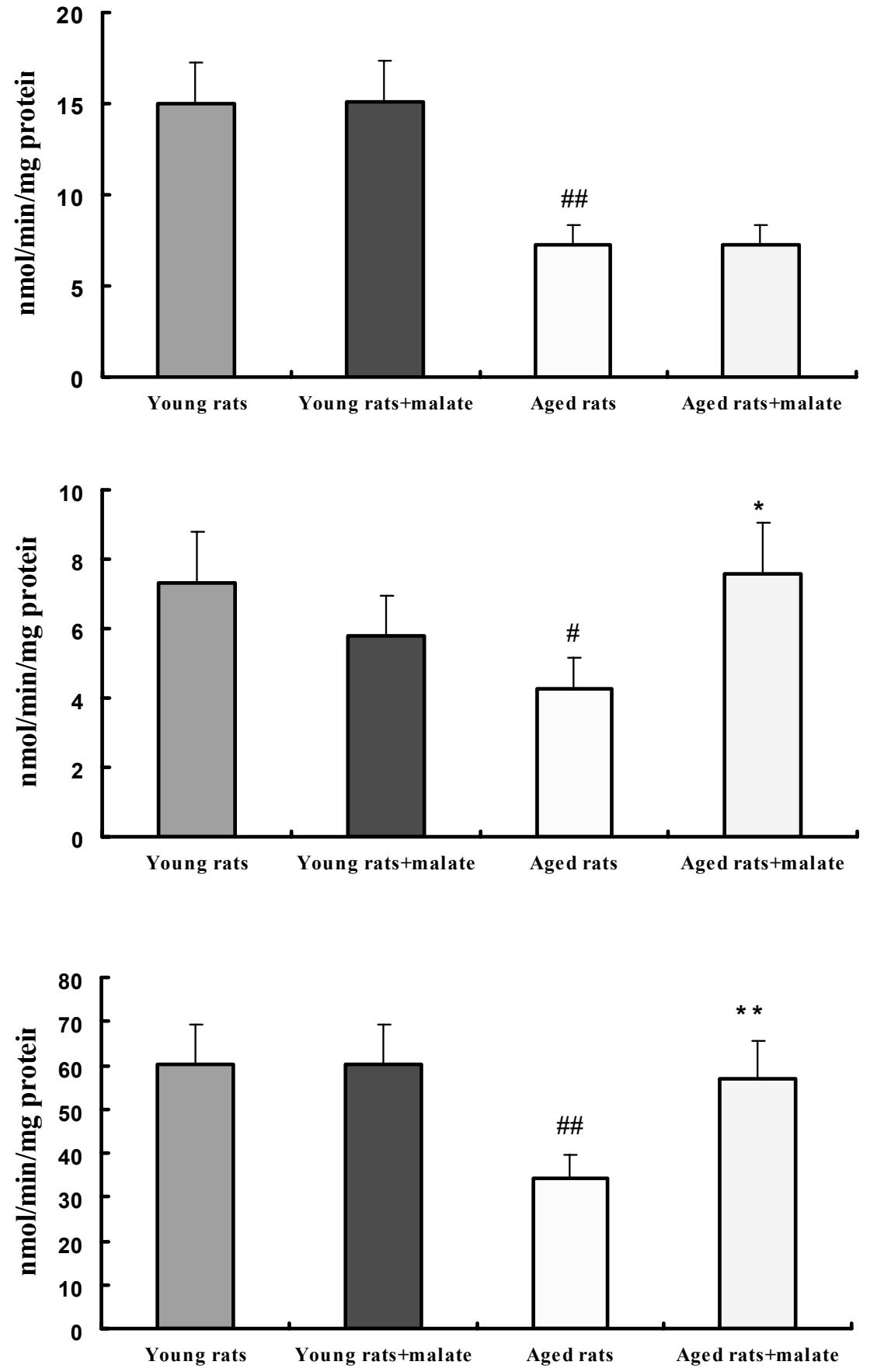

Fig. 3. Activity of succinate dehydrogenase in liver mitochondria of control and malatetreated young and aged rat. Values are the means \pm S.D. $\left(n=6\right.$, respectively). ${ }^{\# \#} P<0.01$ indicates significant difference compared with young rats (Group Ia).
Fig. 4. Activity of NADH-cytochrome c oxidoreductase in liver mitochondria of control and malate-treated young and aged rat. Values are the means \pm S.D. $(n=6$, respectively). ${ }^{\#} \mathrm{P}<0.05$ indicates significant difference compared with young rats (Group Ia); ${ }^{*} \mathrm{P}<0.05$ indicates significant difference compared with aged rats (Group IIa).
Fig. 5. Activity of cytochrome c oxidase in liver mitochondria of control and malatetreated young and aged rat. Values are the means \pm S.D. $\left(n=6\right.$, respectively). ${ }^{\#} P<0.01$ indicates significant difference compared with young rats (Group Ia); $* * \mathrm{P}<0.01$ indicates significant difference compared with aged rats (Group IIa). observed in liver of aged treated rats (Group IIb) compared with aged control rats (Group IIa). L-malate administration caused no significant changes in the activities of both the enzymes in young rats (Group Ib).

\section{Discussion}

Defects of the mitochondrial respiratory chain are increasingly being recognized as important causes of human diseases and may also be a factor in aging (Trounce et al. 1989). Age-associated reductions in the activities of mitochondrial enzyme and mitochondrial membrane potential that were found in the current study support previous findings (Kalaiselvi and Panneerselvam 1998, Hagen et al. 2002). The fluorescent dye R123 was used as a probe for MMP because the dye is well characterized, causes no loss of mitochondrial coupling, and is not toxic at low concentrations (Johnson et al. 1980). Moreover, dye accumulation and fluorescence intensity are stable, allowing accurate measurement of fluorescence characteristics. In this study, a decrease in the membrane potential in aged rats was observed. These 
results suggest oxidative damage to the membranes and this is supported by a decrease in mitochondrial enzymes. Indeed, studies have shown a decrease in membrane potential in mitochondria from aged rats (Hagen et al. 1997). Administration of L-malate to aged rats partially restored the loss of MMP, although the improvement was not as great as observed in mitochondrial enzymes. The improvement of MMP may be for that L-malate increased activity of cytochrome c oxidase, necessary for mitochondrial function. Therefore L-malate supplementation could influence the ability of mitochondria to maintain their function.

In a healthy liver, energy required for all cellular processes is supplied by the mitochondria through the process of oxidative phosphorylation. A series of enzymes including NADH-dehydrogenase, succinate dehydrogenase, NADH-cytochrome c oxidoreductase and cytochrome c oxidase are involved in this process. A significant decline in the levels of succinate dehydrogenase, NADH-cytochrome c oxidoreductase and cytochrome c oxidase in liver of aged rats observed in our study was supported by other extensive studies (MüllerHöcker et al. 1997, Kwong and Sohal 2000, Arivazhagan et al. 2001). NADH-dehydrogenase, a multisubunit integral membrane complex of mitochondrial ETC, constitutes complex I of the electron transport chain, which passes electrons from NADH to coenzyme Q. We found no changes in the activities of NADHdehydrogenase in liver during aging, although a previous report (Arivazhagan et al. 2001) showed a decrease. Such a variation may be caused by different experimental conditions. Administration of L-malate to aged and young rats improved the activity of NADHdehydrogenase. This enhancement of the enzyme activity could be ascribed to the improvement in the rate of malate-aspartate shuttle by L-malate ( $\mathrm{Wu}$ et al. 2007), which would provide the substrate (NADH) for the ETC.

Succinate dehydrogenase is encoded by nuclear DNA which appears to be more resistant to the oxidative stress (Sandhu and Kaur 2003) than mtDNA. It was suggested that a decline in succinate dehydrogenase activity with aging could be secondary to a decline in the levels of active enzyme molecules per mitochondrion, or due to accumulation of altered molecules in the organelle (Drouet et al. 1999). The decreased production of mitochondrial energy, associated with a chronic increase of oxidative stress with aging, can activate the mitochondrial permeability transition pore and initiate apoptosis (Drouet et al. 1999). Succinate dehydrogenase is well coupled with cytochrome bc1 complex (Savitha et al. 2005). In the present study, we observed an agerelated decrease in succinate dehydrogenase activity which is in agreement with other studies (Arivazhagan et al. 2001, Kwong and Sohal 2000). There is a possibility that the phospholipid membrane environment, surrounding the protein complex, may become relatively less optimal during aging. Age-related alterations in the mitochondrial membrane fluidity have indeed been reported (Mecocci et al. 1997), which can have a considerable impact on the activity of the respiratory chain and the generation of proton gradient.

In the present study, we have observed agerelated decreases in the activities of NADH-cytochrome $\mathrm{c}$ oxidoreductase and cytochrome c oxidase. It is reported that the impairment of these enzymes are due to the ROSinduced cardiolipin peroxidation (Hoch 1992, Paradies et al. 2000). This may increase the electron leak from the ETC, generating more superoxide radicals and perpetuating a cycle of oxygen radical-induced damage. The activities of these enzymes are dependent on the levels of cardiolipin. The increase in the activities of these enzymes induced by L-malate administration in aged rats may be due to the fact that L-malate elevates the levels of cardiolipin in liver of aged rats. L-malate increases the TCA metabolism which in turn increases NADPH generation. Therefore, L-malate strengthens the antioxidative defense system by increasing NADPH generation and improving energy status in aged rats. Administration of L-malate to aged rats increases the level of reduced glutathione ( $\mathrm{Wu}$ et al. 2008). Mitochondrial GSH plays a critical role in cell viability through the regulation of mitochondrial inner membrane permeability by maintaining sulfhydryl groups in the reduced state (Fernandez-Checa et al. 1996), thus giving a clue to the increase in the activity of NADHcytochrome c oxidoreductase and cytochrome-c-oxidase (García-Ruiz et al. 1995). The oxidation of various substrates causes a different extent of peroxidative damage. It was found that the other substrate of the TCA cycle, succinate, could recover membrane potential and protect hepatocytes during peroxidative damage (Červinková et al. 2009, Endlicher et al. 2009). Malate is known to facilitate mitochondrial uptake of other carboxylic substrates and mitochondrial malate is responsible for the increased rate of oxidation. Though succinate has beneficial effect of protecting hepatocytes during peroxidative damage, the mechanism is different from the mechanism of L-malate. 
In conclusion, L-malate can improve the activities of electron transport chain enzymes and thereby strengthen the antioxidant defense system.

\section{Conflict of Interest}

There is no conflict of interest.

\section{Acknowledgements}

This study was supported by grants from the Foundation for the Talents of Guangdong Academy of Science and National Natural Science Foundation of China (31000762).

\section{References}

ARIVAZHAGAN P, RAMANATHAN K, PANNEERSELVAM C: Effect of DL-a-lipoic acid on mitochondrial enzymes in aged rats. Chem Biol Interact 138: 189-198, 2001.

BECKMAN KB, AMES BN: The free radical theory of aging matures. Physiol Rev 78: 547-581, 1998.

BENDAHAN D, MATTEI JP, GHATTAS B, CONFORT-GOUNY S, LE GUERN ME, COZZONE PJ: Citrulline/malate promotes aerobic energy production in human exercising muscle. Br J Sports Med 36: 282289, 2002.

BIRCH-MACHIN MA, BRIGGS HL, SABORIDO AA, BINDOFF LA, TURNBULL DM: An evaluation of the measurement of the activities of complexes I-IV in the respiratory chain of human skeletal muscle mitochondria. Biochem Med Metab Biol 51: 35-42, 1994.

BOBYLEVA-GUARRIERO B, LARDY HA: The role of malate in exercise-induced enhancement of mitochondrial respiration. Arch Biochem Biophys 245: 270-276, 1986.

BRADFORD MM: A rapid and sensitive method for the quantization of microgram quantities of protein utilizing the principle of protein-dye binding. Anal Biochem 72: 248-254, 1976.

ČERVINKOVÁ Z, KŘIVÁKOVÁ P, LÁBAJOVÁ A, ROUŠAR T, LOTKOVÁ H, KUČERA O, ENDLICHER R, ČERVINKA M, DRAHOTA Z: Mechanisms participating in oxidative damage of isolated rat hepatocytes. Arch Toxicol 83: 363-372, 2009.

CHANCE B, SIES H, BOVERIS A: Hydroperoxide metabolism in mammalian organs. Physiol Rev 59: 527-605, 1979.

CHAPPEL JB: Systems used for the transport of substrates into mitochondria. Br Med Bull 24: 150-157, 1968.

CORTOPASSI GA, SHIBATA D, SOONG NW, ARNHEIM N: A pattern of accumulation of somatic deletion of mitochondrial DNA in aging tissue. Proc Natl Acad Sci USA 89: 7370-7374, 1992.

DREW B, LEEUWENBRUGH C: Aging and the role of reactive nitrogen species. Ann N Y Acad Sci 959: 66-81, 2002.

DROUET M, LAUTHIER F, CHARMES JP, SAUVAGE P, RATINAND MH: Age associated changes in mitochondrial parameters on peripheral human lymphocytes. Exp Gerontol 34: 69-78, 1999.

ENDLICHER R, KŘIVÁKOVÁ P, RAUCHOVÁ H, NUSKOVÁ H, ČERVINKOVÁ Z, DRAHOTA Z: Peroxidative damage of mitochondrial respiration is substrate-dependent. Physiol Res 58: 685-692, 2009.

FERGUSON M, MOCHETT RJ, SHEN Y, ORR WC, SOHAL RS: Age-associated decline in mitochondrial respiration and electron transport in Drosophila melanogaster. Biochem J 390: 501-511, 2005.

FERGUSON SMF, WILLIAMS GR: The Effect of malate and other dicarboxylic acids on mitochondrial isocitrate metabolism. J Biol Chem 241: 3696-3700, 1966.

FERNANDEZ-CHECA JC, YI J, GARCIARUIZ C, OKHTENS M, KAPLOWITZ N: Plasma membrane and mitochondrial transport of hepatic reduced glutathione. Semin Liver Dis 16: 147-158, 1996.

GARCIA-RUIZ C, COLELL A, MORALES A, KAPLOWITZ N, FERNANDEZ-CHECA JC: Role of oxidative stress generated from the mitochondrial electron transport chain and mitochondrial glutathione status in loss of mitochondrial function and activation of transcription factor nuclear factor-kappa B: studies with isolated mitochondria and rat hepatocytes. Mol Pharmacol 48: 825-834, 1995.

HAGEN TM, LIU J, LYKKESFELDT J, WEHR CM, INGERSOLL RT, VINARSKY V, BARTHOLOMEW JC, AMES BN: Feeding acetyl-Lcarnitine and lipoic acid to old rat significantly improves metabolic function while decreasing oxidative stress. Proc Natl Acad Sci USA 99: 1870-1875, 2002. 
HAGEN TM, YOWE DL, BARTHOLOMEW JC, WHER CM, DO KL, PARK JY, AMES BN: Mitochondrial decay in hepatocytes from old rats: membrane potential declines, heterogeneity and oxidants increase. Proc Natl Acad Sci USA 94: 3064-3069, 1997.

HARMAN D: Aging: a theory based on free radical and radiation chemistry. J Gerontol 11: 340-351, 1956.

HARMAN D: The biological clock: the mitochondria? J Am Geriatr Soc 20: 145-147, 1972.

HOCH FL: Cardiolipins and biomembrane function. Biochim Biophys Acta 1113: 71-133, 1992.

JOHNSON LV, WALSH ML, CHEN LB: Localization of mitochondria in living cells with rhodamine 123. Proc Natl Acad Sci USA 77: 990-994, 1980.

KALAISELVI T, PANNEERSELVAM C: Effect of 1-carnitine on the status of lipid peroxidation and antioxidants in aging rats. J Nutr Biochem 9: 575-581, 1998.

KWONG LK, SOHAL RS: Substrate and site specificity of hydrogen peroxide generation in mouse mitochondria. Arch Biochem Biophys 350: 118-126, 1998.

KWONG LK, SOHAL RS: Age-related changes in activities of mitochondrial electron transport complexes in various tissues of the mouse. Arch Biochem Biophys 373: 16-22, 2000.

MECOCCI P, BEAL MF, CECCHETTI R, POLIDORI MC, CHERUBINI A, CHIONNE F, AVELLINI L, ROMANO G, SENIN U: Mitochondrial membrane fluidity and oxidative damage to mitochondrial DNA in aged and AD human brain. Mol Chem Neuropathol 31: 53-64, 1997.

MIQUEL J, ECONOMOS AC, FLEMING J, JOHNSON JE JR: Mitochondrial role in cell aging. Exp Gerontol 15: 575-591, 1980.

MULLER-HOCKER J, AUST D, ROHRBACH H, NAPIWOTZKY J, REITH A, LINK TA, SEIBEL P, HOLZEL D, HADENBACH B: Defects of the respiratory chain in the normal human liver and in cirrhosis during aging. Hepatology 26: 709-719, 1997.

OZAWA T: Genetic and functional changes in mitochondria associated with aging. Physiol Rev 77: 425-464, 1997.

PARADIES G, PETROSILLO G, PISTOLESE M, RUGGIERO FM: The effect of reactive oxygen species generated from the mitochondrial electron transport chain on the cytochrome c oxidase activity and on the cardiolipin content in bovine heart submitochondrial particles. FEBS Lett 466: 323-326, 2000.

SANDHU SK, KAUR G: Mitochondrial electron transport chain complexes in aging rat brain and lymphocytes Biogerontology 4: 19-29, 2003.

SAVITHA S, SIVARAJAN K, HARIPRIYA D, KOKILAVANI V, PANNEERSELVAM C: Efficacy of levo carnitine and alpha lipoic acid in ameliorating the decline in mitochondrial enzymes during aging. Clin Nutr 24: 794$800,2005$.

SCHOLZ TD, TENEYCK CJ, SCHUTTE BC: Thyroid hormone regulation of the NADH shuttles in liver and cardiac mitochondria. J Mol Cell Cardiol 32: 1-10, 2000.

SHIGENAGA MK, HAGEN TM, AMES BN: Oxidative damage and mitochondrial decay in aging. Proc Natl Acad Sci USA 91: 10771-10778, 1994.

SMITH JA, WEIDEMANN MJ: Further characterization of the neutrophil oxidative burst by flow cytometry. J Immunol Methods 162: 261-268, 1993.

SOHAL RS, DUBEY A: Mitochondrial oxidative damage, hydrogen peroxide release and aging. Free Radic Biol Med 16: 621-626, 1994.

SOHAL RS, SOHAL BH: Hydrogen peroxide release by mitochondria increases during aging. Mech Ageing Dev 57: 187-202, 1991.

RICHTER C, GOGVADZE V, LAFFRANCHI R, SCHLAPBACH R, SCHWEIZER M, SUTER M, WALTER P, YAFFEE M: Oxidants in mitochondria: from physiology to disease. Biochim Biophys Acta 1271: 67-74, 1995.

TROUNCE I, BYRNE E, MARZUKI S: Decline in skeletal muscle mitochondrial respiratory chain function: Possible factor in ageing. Lancet 8639: 637-639, 1989.

WU JL WU QP, HUANG JM, CHEN RY, CAI M, TAN JB: Effects of L-malate on physical stamina and activities of enzymes related to the malate-aspartate shuttle in liver of mice. Physiol Res 56: 213-220, 2007.

WU JL, WU QP, YANG XF, WEI MK, ZHANG JM, HUANG Q, ZHOU XY: L-malate reverses oxidative stress and antioxidative defenses in liver and heart of aged rats. Physiol Res 57: 261-268, 2008. 